\title{
Revisiting the Question of Calculating Tourist Flows in the Russian Federation
}

\author{
Semenova L.V. \\ Immanuel Kant Baltic Federal University \\ Kaliningrad, Russia \\ e-mail: lsemenova@kantiana.ru
}

\author{
Nikolskaya E.Yu. \\ Plekhanov Russian University of Economics, \\ Moscow, Russia \\ e-mail:nik_elen@mail.ru
}

\author{
Kovaleva N.I. \\ Moscow Institute for physical culture, sport and tourism, \\ Moscow, Russia \\ nata60iosif@list.ru
}

\begin{abstract}
The article analyzes the current state of the tourist flows assessment in the Russian Federation. The lack of a precise and clear methodology for tourist flows calculations is one of the main problems, since this indicator is one of the main factors determining the efficiency of the development of tourist destinations, which allows to form an effective strategy for the territory development. As part of the study, the main approaches to the definition of "tourist flow" are identified, concurrently the existing approaches to the calculation of tourists in various territories are presented. The study showed that the Russian Federation does not keep in possession a complete methodology for counting tourists which is convenient for use in as variety of attractive tourist regions. It causes significant problems in the further development planning and for an arrangement of both a budget policy and a general development strategy. Authors indicate that some regions use their own methods for collecting tourist information. Within the framework of the study the main world trends in the field are presented, which can be adapted to Russian environment.
\end{abstract}

Keywords-tourist flow; tourism statistics; statistics; calculation methods.

\section{INTRODUCTION}

Tourism in its essence is a multiplicative collective concept, affecting all elements of the modern society life. The role of tourism within the borders of the country and within its particular parts is constantly increasing due to the ever-increasing influence of modern technologies on the possibility of free tourist movements [1;2].

Tourism activities have a direct and indirect effect on a large number of economic sectors and interconnects them: the development of tourism in the region contributes to the influx of tourists and to the creation of new jobs and employment in the same manner as it contributes to the development of the urban environment, to an increase in population's wealth, increase in the economic efficiency of the tourism industry and growth in the tourism industry share $[3 ; 4 ; 5]$.

The question arises: at what point should a traveler entering the country be considered? How should it be taken into account and in what statistical indicators he is to be reflected?

Common practice is to count tourists entering their destination, that is on the beginning of the trip. However some characteristics (usually related to the costs of a tourist's stay and his expenses during the trip) are not always amenable to reliable calculation. The Russian Federation faces the same challenges since no unified system for calculating the number of tourist movements exist, whereas for many territories this indicator is crucial for making fundamental administrative decisions.

\section{MATERIALS AND METHODS}

Developed countries currently have already a practice of calculating tourist flows, defined by the UNWTO, which is updated in the 2019 Methodological Recommendations (Methodological Notes to the Tourism Statistics Database. Published by the World Tourism Organization (UNWTO), Madrid , Spain, 2019). According to the aforementioned updated methodology, inbound tourist flows are calculated by summing up tourists (who have made at least 1 overnight stay) and excursionists (one-day visitors, which include cruise ship passengers) [6].

In the Russian Federation, Rostourism is responsible for counting tourists. This indicator is determined according to the "Official Statistical Methodology for Estimating the Number of Inbound and Outbound Tourist Trips" which is approved by the Federal State Statistics Service's order 
Federation on the number of foreign students studying in Russian educational institutions and publications of the Organization for Economic Co-operation and Development (OECD) in educational institutions abroad, to be used to estimate the number of tourist inbound and outbound trips, (Table).
According to this order, “... the administrative data of the Border Guard Service of the Federal Security Service of the Russian Federation and the Federal Migration Service, as well as official statistical information generated by the Ministry of Education and Science of the Russian

\begin{tabular}{|l|l|}
\hline \multicolumn{1}{|c|}{ Indicator } & \\
\hline The number of foreign citizens trips to the Russian Federation & Border Service of the FSB of Russia \\
\hline The number of trips of Russian citizens abroad & Border Service of the FSB of Russia \\
\hline The number of foreign citizens registered with the migration for employment & Federal Migration Service of Russia \\
\hline The number of the Russian Federation citizens, travel to work abroad & Federal Migration Service of Russia \\
\hline $\begin{array}{l}\text { The number of foreign students studying in educational institutions of higher education at the } \\
\text { beginning of the school year }\end{array}$ & Ministry of Science and Education \\
\hline $\begin{array}{l}\text { The number of foreign students studying in professional educational organizations training } \\
\text { mid-level specialists at the beginning of the school year }\end{array}$ & Ministry of Science and Education \\
\hline The number of students studying in educational institutions abroad & Organisation for Economic Co-operation and Development \\
\hline
\end{tabular}

The aforementioned order also contains an indication that "... if the same foreign / Russian citizen repeatedly traveled outside his country during the reporting period, then he is counted in the data of the border service as many times as he crossed the state border in one direction. Therefore tourist flows are measured not by the number of tourists, but by the number of trips". It is clear that unfortunately, the data of the FSB border service will not be relevant in calculating the number of tourists traveling to such border countries as Finland, the Baltic states or Poland, partially China, as well as to the CIS countries, Abkhazia and South Ossetia. In these cases the proportion of multiple border crossings is much higher, since most of these crossings are made for personal shopping or (as in the case of Ukraine and a number of other CIS countries) visits of relatives.

So far no regulatory act act has fixed such a fundamental concept as "tourist flow", which should be the basis for the elaboration of tourism development strategies both in the Russian Federation as a whole and in particular territories. In the future this data should be used for elaborating the numerical indicator determining the success / failure these strategies.

Resulting from the analysis of the tourist flow volume in the Russian Federation (in the absence of a legal definition and interpretation of this definition), the indicators are very doubtful [10]

The data presented in their analysis raise serious concerns. It is highly doubtful that there was a tenfold increase in the volume of inbound tourism to the territory of the Russian Federation from 2013 to 2014, as it is stated in official estimates. It is quite clear that during the period of the economic crisis this indicator could not grow so rapidly and, most likely, numbers were obtained thanks to to the new calculation methodology, which is applied since 2014. 


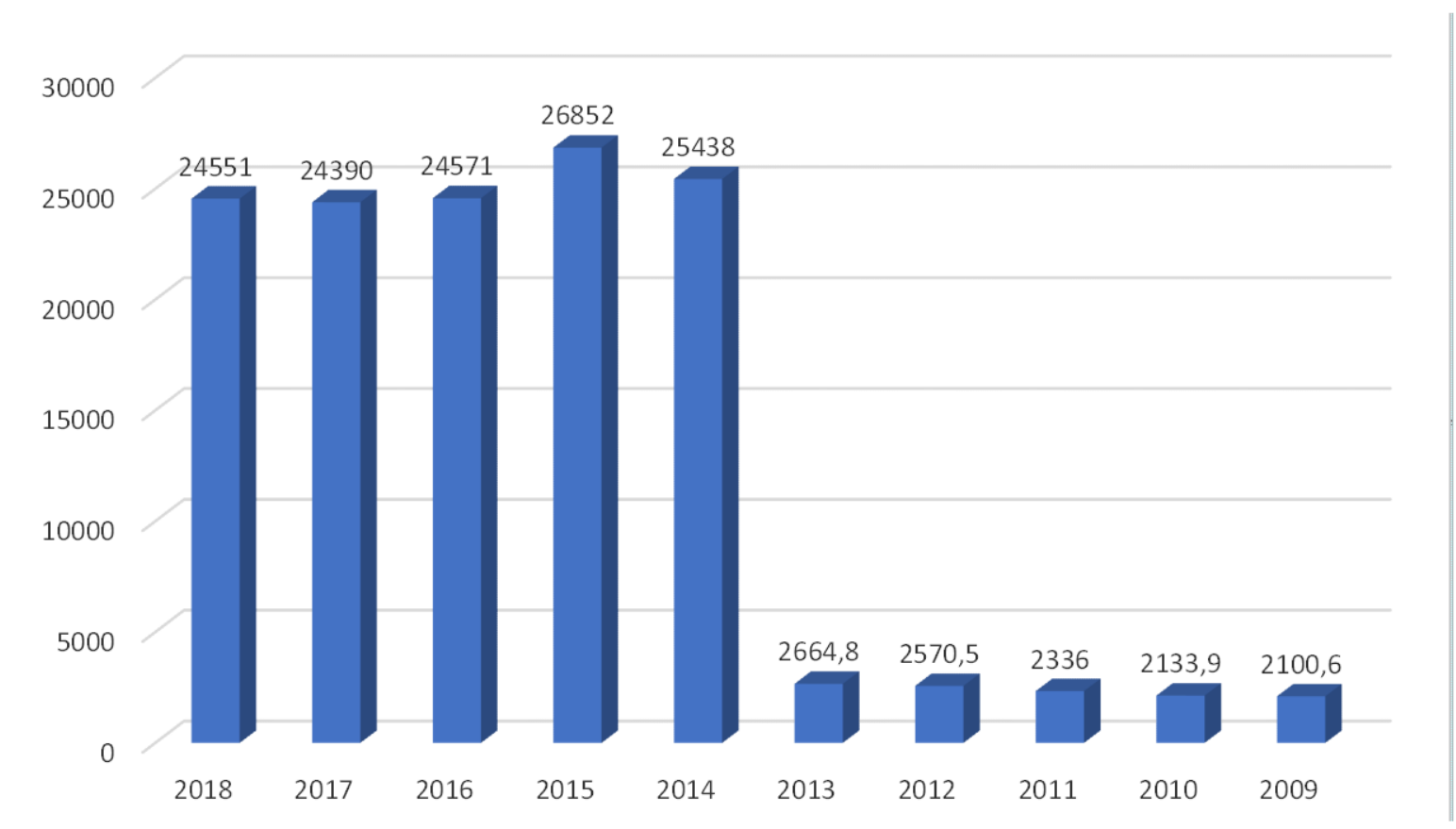

Fig. Dynamics of tourist flows in the Russian Federation [10]

Nowadays in the Russian Federation the Official Statistical Methodology for assessing the number of inbound and outbound tourist trips adopted by the Federal State Statistics Service in 2014 is valid. This method is recommended for usage at the federal level.

The implementation of this technique at the regional level appears to be impossible due to the lack of the necessary static data required to calculate the volume of tourist flow. The imperfection of statistical accounting in the Russian Federation can be heavily ascribed to the fact that currently, only the activities of large and medium-sized enterprises and organizations are subject to statistical accounting in the Russian Federation.

\section{RESULTS}

Assessing the volume of tourist flows and other indicators characterizing the level of tourism development in the region is an important task, the solution of which could positively affect the managing efficacy in the tourism industry. It might also increase the competitiveness of the tourism industry domestically and abroad.

Nowadays the compilation of tourism statistics in foreign practice is regulated by a number of documents. The most significant are listed below:

- International recommendations on tourism statistics, 2008, UNWTO.

- Tourism Satellite Account: Recommended Methodological Framework, 2008, UNWTO.

- Methodological Guide to Tourism Statistics, 2013, Eurostat.
- Guide for European countries on the implementation of the tourism satellite account methodology, Eurostat.

International recommendations on tourism statistics, 2008 are the fundamental document shaping the system of statistical accounting of the tourism industry indicators. It is successfully used in most developed foreign countries - the basis of statistical accounting is a combination of statistical methods with selective sociological surveys of tourists and visitors conducted on a regular basis.

To assess the contribution of the tourism industry to the economy in most developed countries, the Tourism Satellite Account is used. Despite the high level of development of tourism statistics abroad, the main problem in the field is the underestimation of tourists who stay overnight in hotels or other places that do not provide information to the statistical authorities and therefore are not covered by statistical monitoring.

The information collected by the Russian state statistics bodies is incomplete and is characterized by a low level of reliability, which reduces the effectiveness of tourism management at the state and regional levels. Therefore the current state of tourism statistics in Russia can be described as unsatisfactory. There are two methods currently being used to assess the volume of tourist flows.

The official statistical methodology for estimating the number of incoming and outgoing tourist trips involves the use of administrative data of the border service of the FSB of the Russian Federation and the Federal Migration Service, as well as official statistical information generated by the Ministry of Education and Science of the Russian Federation on the number of foreign students studying in Russian educational 
- the method, based on the analysis of tourist accommodation in hotels and other DACs, requires the use of special sample surveys, as well as significant time and financial costs.

A pilot testing of the calculation in select regions of the Russian Federation revealed the problems described above.

For example, when calculating tourist flows in Moscow statisticians take into account the transport statistics of the Moscow transport hub, the number of tourist accommodations in collective accommodation facilities, the data of the border Federal Security Service of the Russian Federation service, and also the indicators of the federal migration service.

Krasnodar Territory calculates the tourist flow considering the indicators of collective accommodation facilities and the estimated indicators of unorganized tourists placed in private apartments.

The Republic of Crimea calculates the tourist flow based on passenger traffic (airport, railway stations. And also takes into account the data of the border service.In addition, the Republic of Crimea weekly monitors organized and unorganized tourists in order to determine the number of tourists staying in private apartments

Suzdal counts collective accommodation facilities, as well as obtains data from the Suzdal Museum-Reserve (although, in our opinion, the indicators of the Museum show rather number of excursionists, not tourists).

\section{CONCLUSION}

Various Russian regions Moscow, St. Petersburg, Krasnodar Territory, Pskov and Yaroslavl Regions, The Republic of Tatarstan, Karelia and other regions attempted to develop new approaches to assess the volume and structure of the tourist flow, the economic efficiency of tourism, as well as bring them closer to international standards. However the unified method is yet to be elaborated.

The main weaknesses of methods used to assess the tourist flow at the regional level is the irregularity of sample sociological surveys. The information received is also most often fragmentary and limited.

\section{References}

\section{DISCUSSION}

Thus, among the main limitations of the methodological approaches recommended for use in the Russian Federation, the following could be distinguished $[11 ; 12]$ :

- imperfection of statistical accounting. So, for example, statistics do not reflect the real situation, in those cases when travel companies are represented by small forms of management and do not provide reporting to statistical authorities. As a result, tourist arrivals are underestimated.

- the official statistical methodology for estimating the number of inbound and outbound tourist trips (approved by Rosstat in 2014) is recommended at the federal level and is not applicable at the regional level due to the lack of statistical data;
[1] Kvon, G.M., Lushchik, I.V., Karpenko, M.A., Zaitseva, N.A., Kulkov, A.A., Galushkin, A.A., Yakupova, N.M. Regional investment policy: analysis and assessment of the investment environment state. Eurasian Journal of Analytical Chemistry. 2017,12(5b), pp. 835-853.

[2] Zaitseva, N.A., Semenova, L.V., Garifullina, I.V., Larionova, A.A., Trufanova, S.N. 2016, Transfrontier Cooperation Strategy Development Based on Utilization Efficiency Increase of Tourism and Recreational Territory Potential. IEJME -Mathematics education, 11(7), 2537-2546. I.S. Jacobs and C.P. Bean, "Fine particles, thin films and exchange anisotropy," in Magnetism, vol. III, G.T. Rado and H. Suhl, Eds. New York: Academic. 1963, pp. 271-350.

[3] The forecast of long-term social and economic development of the Russian Federation for the period until 2030 (2013, March) was developed by the Ministry of Economic Development of the Russian Federation. In Consultant Plus, information and legal system. Retrieved September 02, 2019. URL: from http://economy.gov.ru/minec/activity/ sections/macro/prognoz/doc20130325_06 
[11] Zaitseva N.A., Semenova L.V., Garifullina I.V., Larionova A.A., Trufanova S.N. Transfrontier cooperation strategy development based on utilization efficiency increase of tourism and recreational territory potential. IEJME: MATHEMATICS EDUCATION. 2016, 11(7), pp. 2537-2546

[5] Porter, M. International competition. Competitive advantages of countries. Moscow, Alpina Pablisher. 2017.

[6] Methodological Notes to the Tourism Statistics Database. Published by the World Tourism Organization (UNWTO), Madrid, Spain. 2019.

[7] Federal State Statistics Service's order (order No. 510 of 08/12/2014. Retrieved September 02, 2019.

[8] In Consultant Plus, information and legal system. Retrieved October 25, 2017. URL:http://www.consultant.ru/document/cons_doc_LAW_22142/

[9] Prikaz-Rosstata-ot-12.08.2014-N-510/. URL: http://rulaws.ru/acts/

[10] Federal State Statistics Service's order. URL: http://www.gks.ru/wps/ wcm/connect/rosstat_main/rosstat/ru/statistics/ August. 15, 2019

[12] Nikolskaya E.Yu., Pasko O.V., Volkova I.A, Anikina E.N., Lebedeva O.E. Modeling the competitive advantage of companies within the hotel industry in a region. 2018, 7 (3.15), pp. 293-295.

[13] Alexsandr S. Kuznetsov, Zinaida M. Kuznetsova. Integrated application of rehabilitation means in circannian training cycle of highly-qualified greco-roman style wresltlers. Pedagogico-psychological and medicobiological problems of physical culture and sport. 2017, vol. 12(4), pp. 6-14. DOI: 10/14526/04_2017_259. 